\title{
Energy storage in hybrid organic-inorganic materials hexacyanoferrate-doped polypyrrole as cathode in reversible lithium cells
}

\author{
Torres-Gomez, G,; Skaarup, Steen; West, Keld; Gomez-Romero, P
}

Published in:

Journal of The Electrochemical Society

Link to article, DOI:

$10.1149 / 1.1393562$

Publication date:

2000

Document Version

Publisher's PDF, also known as Version of record

Link back to DTU Orbit

Citation (APA):

Torres-Gomez, G., Skaarup, S., West, K., \& Gomez-Romero, P. (2000). Energy storage in hybrid organicinorganic materials hexacyanoferrate-doped polypyrrole as cathode in reversible lithium cells. Journal of The Electrochemical Society, 147(7), 2513-2516. https://doi.org/10.1149/1.1393562

\section{General rights}

Copyright and moral rights for the publications made accessible in the public portal are retained by the authors and/or other copyright owners and it is a condition of accessing publications that users recognise and abide by the legal requirements associated with these rights.

- Users may download and print one copy of any publication from the public portal for the purpose of private study or research.

- You may not further distribute the material or use it for any profit-making activity or commercial gain

- You may freely distribute the URL identifying the publication in the public portal 


\title{
Energy Storage in Hybrid Organic-Inorganic Materials Hexacyanoferrate-Doped Polypyrrole as Cathode in Reversible Lithium Cells
}

\author{
G. Torres-Gómez, ${ }^{\mathrm{a}}$ S. Skaarup, ${ }^{\mathrm{b}}$ K. West, ${ }^{\mathrm{b}, *}$ and P. Gómez-Romero ${ }^{\mathrm{a}, *, \mathrm{z}}$ \\ ${ }^{a}$ Institut de Ciència de Materials de Barcelona, Barcelona, Spain \\ ${ }^{b}$ Department of Chemistry, Technical University of Denmark, DK-2800 Lyngby, Denmark
}

A study of the hybrid organic-inorganic hexacyanoferrate-polypyrrole material as a cathode in rechargeable lithium cells is reported as part of a series of functional hybrid materials that represent a new concept in energy storage. The effect of synthesis temperatures of the hybrid in the specific capacity obtained from the cell is discussed. However specific capacities are obtained for materials synthesized at lower temperatures $\left(0^{\circ} \mathrm{C}\right)$. The preparation method of the electrodes is also a parameter of great importance: thin film cathodes made with poly(vinylidene fluoride) as a binder and Super P carbon as conducting additive show higher specific capacities than powder cathodes. These materials present modest specific capacities of up to $69 \mathrm{Ah} / \mathrm{kg}$ but withstand repeated cycles of charge/discharge with no loss of capacity, even with an initial gain during the first 60 cycles. (c) 2000 The Electrochemical Society. S0013-4651(00)04-075-1. All rights reserved.

Manuscript received April 20, 2000.

Conducting organic polymers (COPs) have been the subject of great interest in recent years due to their multiple applications as supercapacitors, catalysts, actuators, electrochemical and photoelectrochemical devices, sensors, photoconductors, batteries, etc. ${ }^{1-5}$ These applications are based on the combination of properties of low weight, processability, electronic semiconductivity, and reversible redox chemistry.

When applied as electrodes for batteries, however, COPs have an important disadvantage. When a p-doped COP is reduced, the anions present in the structure to compensate the positive charges of the doped polymer are expelled from the polymeric matrix to the electrolyte. In combination with a cation inserting electrode (like metallic $\mathrm{Li}$ or carbon) the net transfer reaction is not transport of $\mathrm{Li}$ between the electrodes as in the high energy density lithium cells, but rather absorption/dissolution of electrolyte salt. Such a reaction has a limited energy density due to the relatively small changes in electrolyte concentration that are acceptable in this type of battery.

To avoid this limitation, we have explored the synthesis of hybrid organic-inorganic materials based on COPs and electroactive inorganic anions dispersed at the molecular level. Such synthesis offers a great opportunity to couple the conducting properties of COPs with the specific electroactivity of the doping components. The molecular nature of the anions inserted, such as $\left[\mathrm{PMo}_{12} \mathrm{O}_{40}\right]^{3-}$, allowed us to obtain cation-inserting plastic electrodes. ${ }^{6-11}$

Here we study a new hybrid organic-inorganic material in which hexacyanoferrate $(\mathrm{HCF})$ is introduced as the electroactive anion and polypyrrole is used as a conducting polymeric matrix. The synthesis and electrochemical characterization of this material has been previously reported in detail. ${ }^{12}$ In the present work we report the performance of the PPy/HCF hybrid as cathode in rechargeable lithium cells. This hybrid is a new compound within a series of materials that represent a novel concept in the general field of functional materials. In addition to their fundamental interest, the energy storage applications that we suggest are just one of many possible areas in which this kind of material could be used.

\section{Experimental}

Pyrrole (Aldrich) was vacuum-distilled and stored under dark conditions in nitrogen at $4^{\circ} \mathrm{C}$ before use. Other reagents were used as received.

HCF-doped polypyrrole was prepared by oxidative polymerization of pyrrole by chemical synthesis, testing three different methods described in detail elsewhere. ${ }^{12}$

The first method involved ion-exchange of a $0.2 \mathrm{M}$ solution of $\mathrm{K}_{3} \mathrm{Fe}(\mathrm{CN})_{6}$ in order to exchange $\mathrm{K}^{+}$for $\mathrm{H}^{+}$ions and use the acidic

\footnotetext{
* Electrochemical Society Active Member.

z E-mail: pedro.gomez@icmab.es
}

product to polymerize pyrrole to form the hybrid. A second synthetic procedure consisted of a modification where $\mathrm{K}_{3}\left[\mathrm{Fe}(\mathrm{CN})_{6}\right]$ was treated with $\mathrm{HClO}_{4}$ and the resulting $\mathrm{KClO}_{4}$ precipitate eliminated prior to the reaction of hexacyanoferrate with pyrrole to yield the hybrid. In a final modification of this procedure we found that the synthesis of the hybrid could be performed in a one-pot synthesis without the incorporation of $\mathrm{ClO}_{4}^{-}$anions to the polymer, ${ }^{12}$ which would compete with hexacyanoferrate for the doping of polypyrrole and would be detrimental to the performance of the electrode. Thus, for the preparation of the active electrode material, $25 \mathrm{~mL}$ of a $1.8 \mathrm{M}$ solution of $\mathrm{HClO}_{4}$ in water was added dropwise to a stirred solution of $25 \mathrm{~mL}$ of $0.2 \mathrm{M}$ pyrrole and $3.790 \mathrm{~g}$ of $\mathrm{K}_{3}\left[\mathrm{Fe}(\mathrm{CN})_{6}\right]$ in water. The mixture was kept cold in an ice bath and stirred for $30 \mathrm{~min}$. The black solid formed was filtered off, washed repeatedly with water (until the white solid $\mathrm{KClO}_{4}$ also formed in the reaction was completely removed), then washed with ethanol and dried under vacuum for at least $12 \mathrm{~h}$.

Although no such event has occurred in our experiments, we should note that the combination of the strongly oxidizing $\mathrm{KClO}_{4}$ with organic matter (when dry) might lead to violent combustion activated by heat or friction. Hence, it is important to thoroughly wash the heterogeneous mixture in order to remove completely the potassium perchlorate by-product.

Compact reversible electrochemical cells were set up in Swagelok test cells, using a Labconco 50700 glove box allowing for water and oxygen removal to less than 1 and $5 \mathrm{ppm}$, respectively. $\mathrm{Li}$ foil (16-13 $\mathrm{mm}$ diam and $0.1 \mathrm{~mm}$ thick) was used as negative electrode and a solution of $\mathrm{LiPF}_{6} 1 \mathrm{M}$ ethylene carbonate/diethylene carbonate (EC/DEC) was used as electrolyte. The cathode was a film made by mixing the PPy/HCF hybrids and Super-P carbon and polyvinylidene fluoride (PVDF) (used as a binder) in acetone, and subsequent evaporation of the solvent at room temperature. The cells were tested with charge/discharge cycles performed with an Arbin model BT2042 potentiostat.

Two cycling methods have been used.

1. Galvanostatic charge and discharge between two potential limits. In this case, all cells were cycled using a discharge rate of $\mathrm{C} / 30$ (the rate that will consume the theoretical capacity in $30 \mathrm{~h}$ ). The disadvantage of this method is that the electrode does not reach the equilibrium state at any point in the cycle.

2. Galvanostatic charge and discharge between two potential limits, followed by a potentiostatic step at the limiting potentials until the current has dropped to less than $50 \%$ of the initial value. In this way, an equilibrium state is approached at these points.

Electrochemical studies were carried out with a software-controlled EG\&G PAR207A potentiostat/galvanostat, with counter electrode and reference connections to the lithium anode, and the working electrode to the hybrid cathode. 


\section{Results and Discussion}

Effect of synthesis temperature on the hybrids.-In a previous work $^{12}$ we described the influence of the reaction temperature on the conductivity of the hybrids $\mathrm{PPy} / \mathrm{HCF}$, showing that the higher the synthesis temperature the lower the conductivity. This was attributed to an increase in the number of defects in the polymer structure, as these defects break the delocalization through the $\pi$ system, and also to an increase in doping $\mathrm{Fe}(\mathrm{CN})_{6}$ content. $^{12}$ It is possible to calculate the specific capacity of different lithium batteries (electrolyte $1 \mathrm{M} \mathrm{LiPF}_{6}$ in EC/DEC) through the area of cyclic voltammograms. When the cathode is a thin film made using hybrids obtained at different temperatures, the specific capacity is always higher when the reaction temperature is lower, for each sweep rate (Fig. 1).

Thus the reaction temperature also affects the electrochemical behavior of the hybrids and their properties as electrodes in lithium cells. From this result we conclude that the best samples to be used as cathodes in rechargeable lithium cells are those obtained at lower temperatures, especially at $0^{\circ} \mathrm{C}$, because they present higher values of specific capacity.

The hybrid PPy/HCF as cathode in rechargeable lithium cells.-Several previous studies have reported the expulsion of the $\mathrm{Fe}(\mathrm{CN})_{6}$ anion from $\mathrm{PPy} / \mathrm{Fe}(\mathrm{CN})_{6}$ materials obtained electrochemically when the hybrid materials are reduced in an aqueous media. ${ }^{13-16}$ This behavior has been also observed by the authors, both in $\mathrm{HClO}_{4}$ and $\mathrm{LiClO}_{4}$ aqueous media. ${ }^{17}$ Nevertheless, when the same electrochemical experiments are carried out in an organic electrolyte, $1 \mathrm{M} \mathrm{LiClO}_{4}$ in ethylene carbonate/dimethoxyethane (EC/DME) 1:1, no $\mathrm{Fe}(\mathrm{CN})_{6}$ was found in the electrolyte, even when the hybrid was subject to reduction potentials (as low as $-0.4 \mathrm{~V} v s$. $\mathrm{Ag} / \mathrm{AgCl}$ ). ${ }^{12}$ This implies that in rechargeable lithium cells (where organic electrolytes like the one mentioned above are used) it is $\mathrm{Li}^{+}$ions diffusing in and out of the polymeric matrix rather than expulsion of anions that are responsible for the charge transfer. This behavior would be similar to the cation-insertion mechanism found for other organicinorganic hybrids obtained previously in our laboratory. ${ }^{6-11}$

Cells analyzed at constant current $(C / 30)$.- - During the first experiments with rechargeable lithium cells, the hybrid was used as a powder cathode, mixed with $20 \%$ of Super P carbon (electrolyte $1 \mathrm{M}$ $\mathrm{LiPF}_{6}$ in EC/DME 1:1). Figure 2 shows the first cycles of that cell.

However, this method has an important problem: parameters such as thickness or porosity of the cathodes, important when the kinetic behavior of the material is considered, are not controlled. In order to avoid this disadvantage, several films of the hybrid were prepared using PVDF as a binding agent and Super P carbon to improve the conductivity of the positive electrode (cathode). Figure 3 shows the behavior of a cell with this kind of thin cathode.

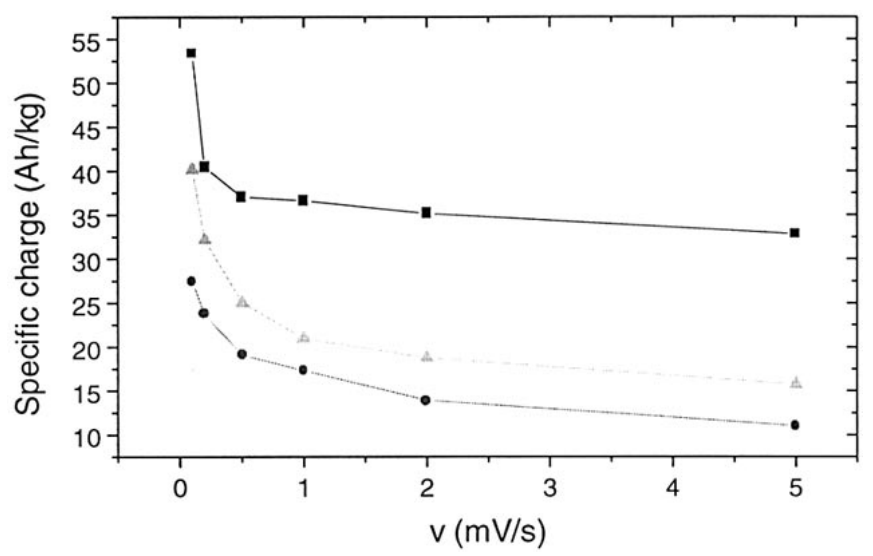

Figure 1. Plot of specific capacity (obtained from the area of CVs made at different sweep rates) $v s$. sweep rate $(v)$ for lithium cells with cathodes of $\mathrm{PPy} / \mathrm{HCF}$ hybrids obtained at (匹) $0^{\circ},(\triangle) 27^{\circ}$, and $(\bigcirc) 42^{\circ} \mathrm{C}$.



Figure 2. First discharge and charge cycles of a lithium cell where the positive electrode is $\mathrm{PPy} / \mathrm{HCF}$ powder (obtained at $0^{\circ} \mathrm{C}$ ) mixed with $20 \%$ of carbon Super P. $V_{\text {initial }}=3.55 \mathrm{~V}, V_{\min }=1.8 \mathrm{~V}, V_{\max }=3.6 \mathrm{~V}$.

When the specific capacities of those cells are compared (Fig. 4), it can be seen that the use of the cathode of the hybrid as a thin film improves the specific capacity of the cell, probably due to improved electrode kinetics.

The cycles shown in Fig. 3 and 4 show some relevant features. First, there is in both a significant irreversible capacity. This behavior has been reported earlier for other COPs and assigned to a particularly stable tertiary structure between the charged chain segments and the solvated counterions in polypyrrole, so that during the first discharging scan this structure is somewhat altered. ${ }^{18,19}$ Second, the capacity of the cells increases with the number of cycles in both cases.

Cells analyzed at constant current; maintaining the limit potentials.-As mentioned above, this method represents a combination of conventional galvanostatic charge and discharge and a potentiostatic treatment at the potential limits until the current measured at this potential is less than a predetermined value. In our study the criteria for continuing the potential sweep has been that the current would drop to less than $50 \%$ of the initial current. In all cells the cathode used was a thin film of the hybrid, PVDF, and Super P carbon. Three cells were set up with hybrid materials obtained at dif-

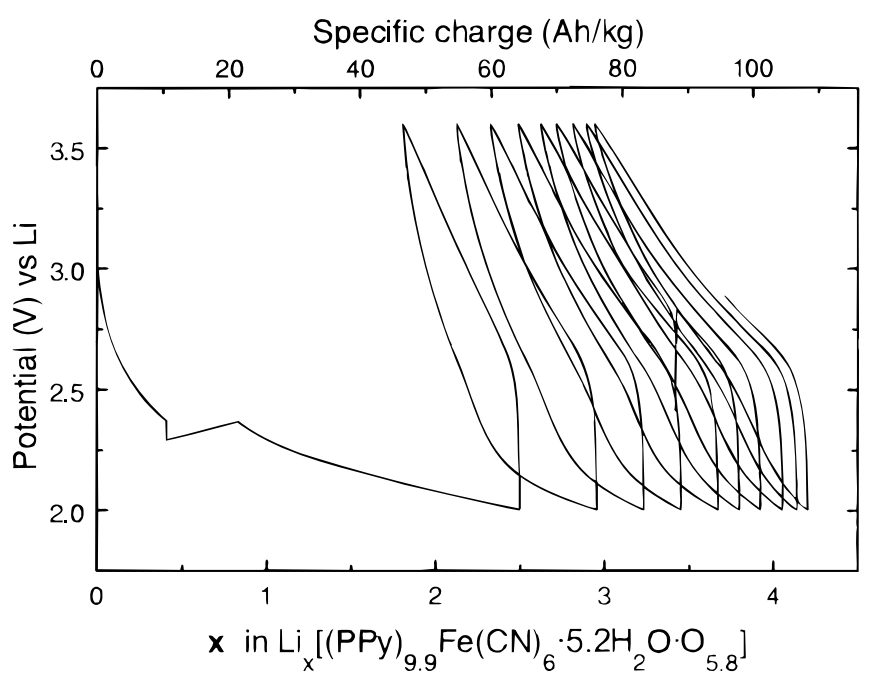

Figure 3. First discharge and charge cycles of a lithium cell where the positive electrode is a thin film made from $\mathrm{PPy} / \mathrm{HCF}$ (obtained at $0^{\circ} \mathrm{C}$ ) using PVDF and carbon Super P. $V_{\text {initial }}=3.06 \mathrm{~V}, V_{\min }=2.0 \mathrm{~V}, V_{\max }=3.6 \mathrm{~V}$. 


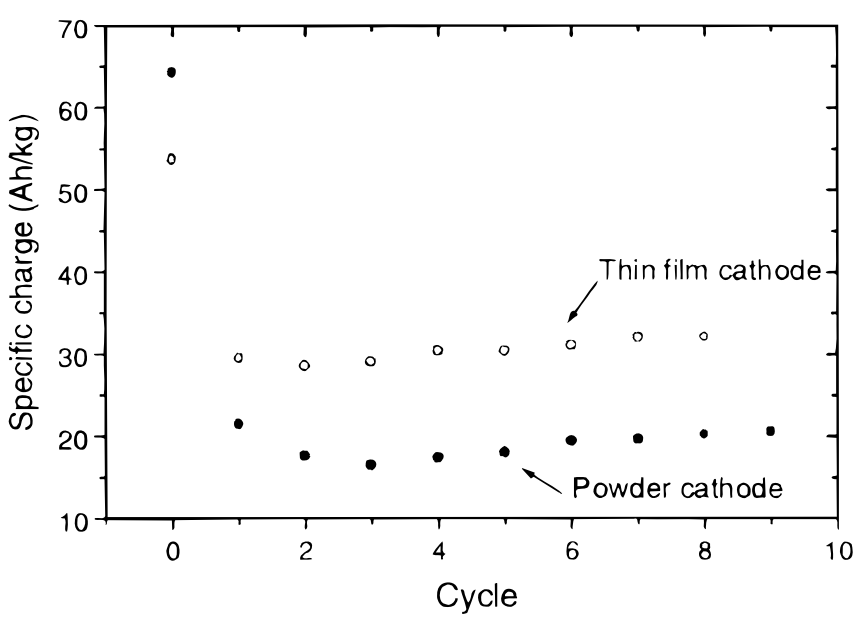

Figure 4. Specific capacity of each $(\bullet)$ discharge cycle in rechargeable lithium cells where the positive electrode is made with PPy/HCF hybrid obtained at $0^{\circ} \mathrm{C}$. The hybrid has been used as a $(\bullet)$ powder or $(\bigcirc)$ thin film.

ferent temperatures: 0,27 , and $42^{\circ} \mathrm{C}$. The electrolyte used was $1 \mathrm{M}$ $\mathrm{LiPF}_{6}$ in EC/DEC $1: 1$.

Figure 5 shows the cycles corresponding to the cell with the hybrid prepared at $0^{\circ} \mathrm{C}$. Note that under the present cycling conditions the specific capacity of the cell increased with the number of cycles. Although only 60 cycles have been plotted, this cell was cycled 98 times, and the highest specific capacity was obtained in cycle 94 (69 Ah/kg, theoretical value of $103 \mathrm{Ah} / \mathrm{kg}$ calculated for the insertion of $4 \mathrm{Li}^{+}$ions per formula unit $\left(\mathrm{C}_{4} \mathrm{H}_{3} \mathrm{~N}\right)_{9.9} \cdot \mathrm{Fe}(\mathrm{CN})_{6} \cdot 5.2 \mathrm{H}_{2} \mathrm{O} \cdot \mathrm{O}_{5.8}$. The increment of specific capacity during cycling may be due to the opening of the structure of the polymer in successive oxidation and reductions, so that there is an improvement in the amount of material effectively active and in the kinetics of the whole process.

For cathodes made with hybrids obtained at higher temperatures (27 and $42^{\circ} \mathrm{C}$, Fig. 6 and 7) the specific capacity is smaller. In addition, these cells show a large polarization, probably due to the low conductivity of the cathode.

Note that cycling for these latter two cells was carried out under more strenuous conditions than the one in Fig. 5. In principle this could also play a role in their poorer performance. Nevertheless, the hybrid obtained at $42^{\circ} \mathrm{C}$ has also been analyzed under the same con-

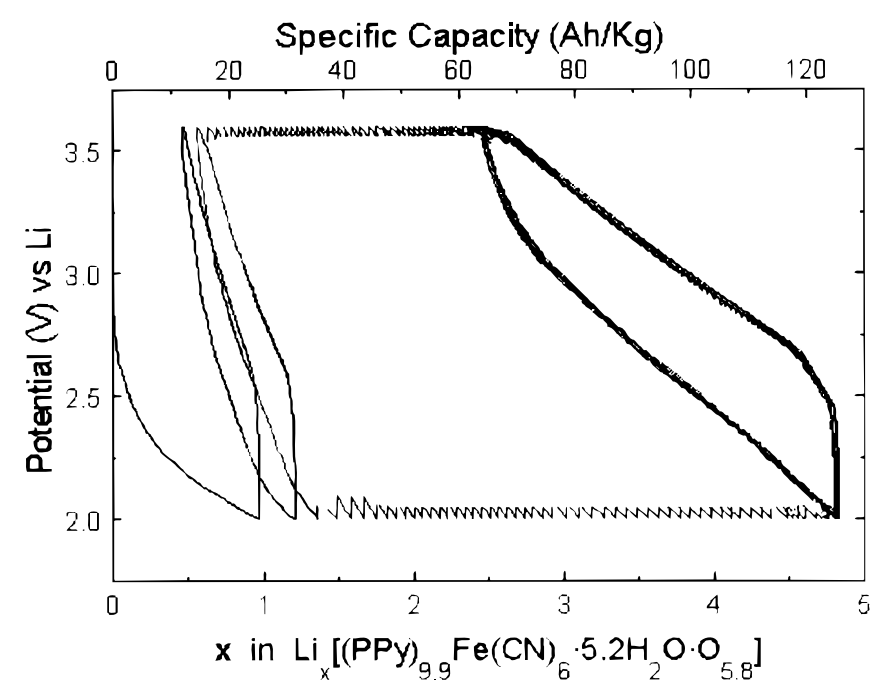

Figure 5. Discharge and charge cycles of a lithium cell where the positive electrode is a thin film made from PPy/HCF (obtained at $\left(0^{\circ} \mathrm{C}\right)$ using PVDF and carbon Super P. $V_{\text {initial }}=2.97 \mathrm{~V}, V_{\min }=2.0 \mathrm{~V}, V_{\max }=3.6 \mathrm{~V}, I_{\text {discharge }}=$ $I_{\text {charge }}=25 \mu \mathrm{A}$. Only cycles 1,2 , and 55-60 are shown for clarity.

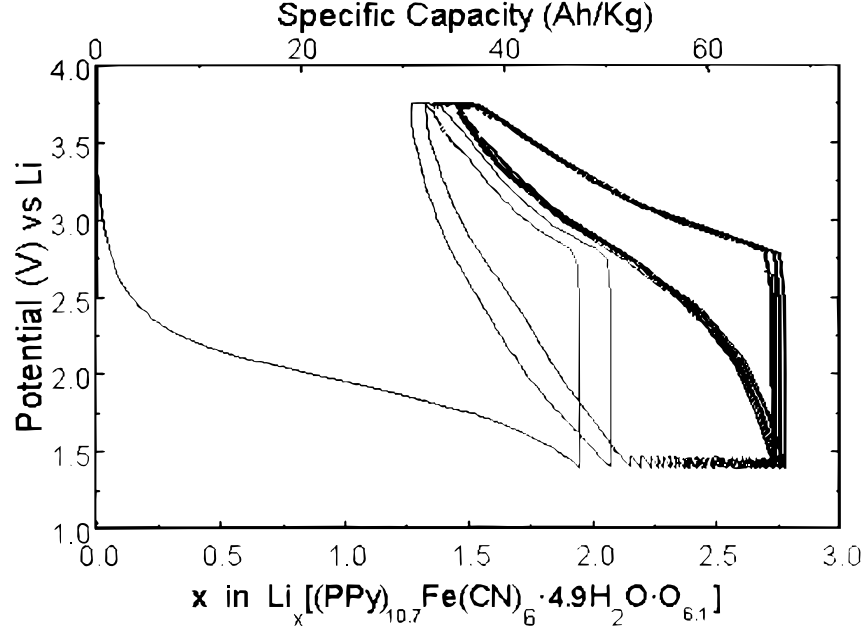

Figure 6. First discharge and charge cycles of a lithium cell where the positive electrode is a thin film made from $\mathrm{PPy} / \mathrm{HCF}$ (obtained at $27^{\circ} \mathrm{C}$ ) using PVDF and carbon Super P. $V_{\text {initial }}=3.11 \mathrm{~V}, V_{\min }=1.4 \mathrm{~V}, V_{\max }=3.75 \mathrm{~V}$, $I_{\text {discharge }}=I_{\text {charge }}=100 \mu \mathrm{A}$. Only cycles 1,2 , and 55-60 are shown for clarity.

ditions of the previous cell $\left(V_{\text {initial }}=2.97 \mathrm{~V}, V_{\min }=2.0 \mathrm{~V}, V_{\max }=\right.$ $3.6 \mathrm{~V}, I_{\text {discharge }}=I_{\text {charge }}=25 \mu \mathrm{A}$ ) without yielding better results.

Therefore, there are clear differences between the hybrids obtained at different temperatures when their behavior as cathodes is analyzed in rechargeable lithium cells. The hybrid materials prepared at lower temperatures show a better specific capacity and good cyclability (Fig. 8). This result is in good agreement with the behavior observed for the cells as analyzed by cyclic voltammetry above (see Fig. 1).

\section{Conclusions}

$\mathrm{PPy} / \mathrm{HCF}$ hybrids can be used as cathodes in rechargeable lithium cells which can be cycled repeatedly (up to 100 cycles in the present study). These cells show a high irreversible capacity, similar to the behavior of other conducting organic polymers. On the other hand, they can be recharged for more than 100 cycles, with the added feature that, in some cases, the reversible specific capacity is increased with the number of cycles and then stabilizes. The hybrids obtained at lower temperature $\left(0^{\circ} \mathrm{C}\right)$ have a higher specific capacity

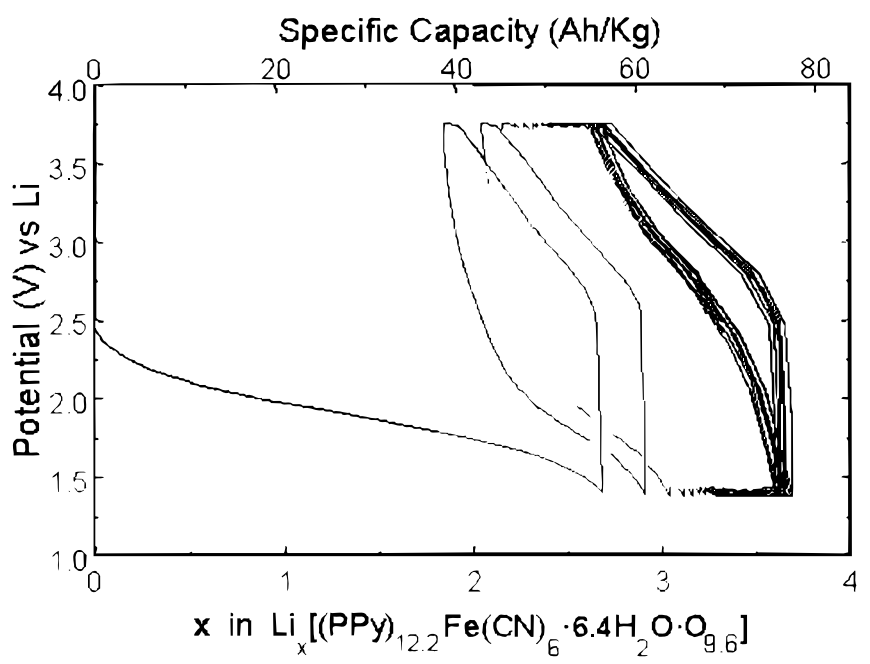

Figure 7. First discharge and charge cycles of a lithium cell were the positive electrode is a thin film made from $\mathrm{PPy} / \mathrm{HCF}$ (obtained at $42^{\circ} \mathrm{C}$ ) using PVDF and carbon Super P. $V_{\text {initial }}=2.45 \mathrm{~V}, V_{\min }=1.4 \mathrm{~V}, V_{\max }=3.75 \mathrm{~V}$, $I_{\text {discharge }}=I_{\text {charge }}=100 \mu \mathrm{A}$. Only cycles 1,2 , and 55-60 are shown for clarity. 


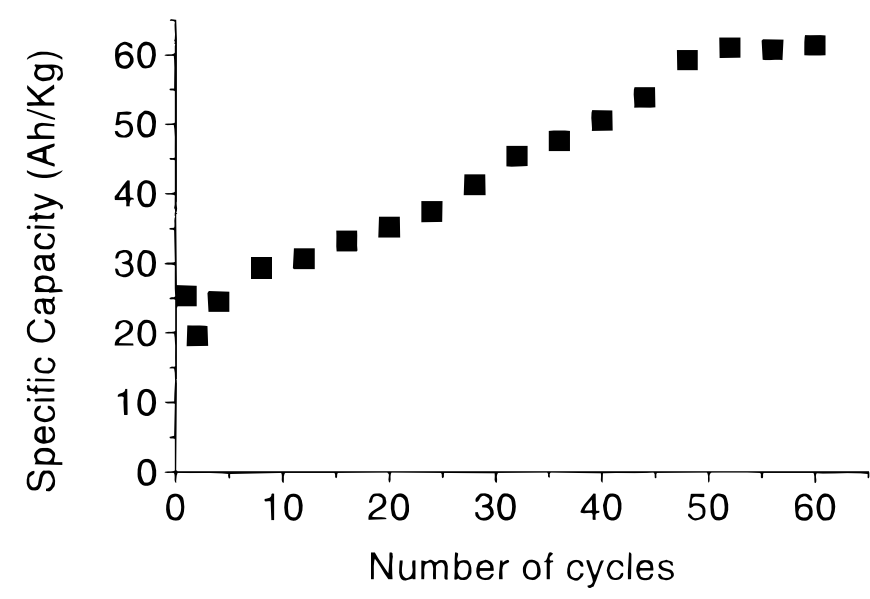

Figure 8. Evolution of specific capacity with the number of cycles for the lithium cell where the positive electrode is a thin film made from PPy/HCF (obtained at $0^{\circ} \mathrm{C}$ ) using PVDF and carbon Super P (Fig. 5).

than the ones synthesized at higher temperatures, which, at the same time, show a large polarization due to the low conductivity of the materials. The preparation of the electrodes is also an important factor for the optimization of the specific capacity of the cells, as shown by the improved results of films made with carbon and PVDF. Finally, note that the materials described represent a new concept rather than an optimized technology in the field of energy storage and that there is room for improvement concerning specific discharge at higher rates. Also note that the present PPy/HCF hybrid materials represent a step forward in the development of these novel hybrid molecular materials. They represent an improvement in specific capacity and cyclability, with respect to the values obtained hitherto for other molecular organic-inorganic hybrids prepared in our laboratory. The cyclability of the present material is especially promising and after optimization could make it a good candidate for specific applications such as low power thin polymer rechargeable systems.

\section{Acknowledgments}

This work was funded by CICYT (Spain) (MAT98-0807-C0202). We thank the Ministry of Education and Culture (Spain) for a predoctoral fellowship awarded to G.T.G.

\section{References}

1. S. Roth and W. Graupner, Synth. Met., 55-57, 3623 (1993)

2. J. S. Miller, Adv. Mater., 5, 587 (1993).

3. J. S. Miller, Adv. Mater, 5, 671 (1993).

4. A. G. MacDiarmid, Synth. Met., 84, 27 (1997).

5. P. Novák, K. Müller, K. S. V. Santhanam, and O. Haas, Chem. Rev., 97, 207 (1997)

6. M. Lira-Cantú and P. Gómez-Romero, in Recent Research Developments in Physical Chemistry, S. G. Pandalai, Editor, Transworld Research Network, Trivandrum, India (1997).

7. P. Gómez-Romero and M. Lira-Cantú, Adv. Mater., 9, 144 (1997).

8. P. Gómez-Romero, N. Casañ-Pastor, and M. Lira-Cantú, Solid State Ionics, 101103, 875 (1997)

9. M. Lira-Cantú and P. Gómez-Romero, Chem. Mater., 10, 698 (1998).

10. M. Lira-Cantú and P. Gómez-Romero, Ionics, 3, 194 (1997).

11. P. Gómez-Romero and M. Lira-Cantú in Lithium Polymers Batteries, J. Broadhead and B. Scrosati, Editors, PV 96-17, p. 158, The Electrochemical Society Proceedings Series, Pennington, NJ (1997).

12. G. Torres-Gómez and P. Gómez-Romero, Synth. Met., 98, 95 (1998).

13. L. L. Miller, B. Zinger, and Q. Zhou, J. Am. Chem. Soc., 109, 2267 (1987).

14. G. Lian and S. Dong, J. Electroanal. Chem., 260, 127 (1989).

15. M. Tölgyesi, A. Szücs, C. Visy, and M. Novák, Electrochim. Acta, 40, 1127 (1995).

16. B. Zinger and L. L. Miller, J. Am. Chem. Soc., 106, 6861 (1984).

17. G. Torres-Gómez, M.S. Thesis, University Autonoma de Barcelona, Barcelona, Spain (1998)

18. P. Novák and W. Vielstich, J. Electrochem. Soc., 137, 1681 (1990).

19. J. Heinze and M. Dietrich, Mater. Sci. Forum, 42, 63 (1989). 